\title{
EXCLUSIVE ENDOSCOPIC CHOLESTEATOMA SURGERY
}

\author{
Dhakeswar Singh Potsangbam
}

${ }_{1}^{1}$ Associate Professor, Department of Otorhinolaryngology, J. N. Institute of Medical Sciences, Porompat, Imphal, Manipur, India.

\section{ABSTRACT}

\section{BACKGROUND}

Microscopic ear surgery had been the mainstay of the cholesteatoma surgery. Canal wall up (CWU) surgeries were employed to allow water activities after surgery. Canal wall down (CWD) surgeries were employed to avoid second look surgery to avoid recurrences. Hidden areas like sinus tympani, facial recess were frequent areas of recurrences and combined approach by posterior tympanotomy through mastoid was improvised to address the residual cholesteatoma in hidden areas. But the recurrence rate of cholesteatoma remained high. Endoscopes were introduced in the 1990s. Endoscopes increased accessibility and the endoscope assisted cholesteatoma surgery improved the results and reduced recurrence rate of cholesteatoma. But surgery of cholesteatoma by endoscope remained confined to attic, aditus and small mastoid antrum.

\section{MATERIALS AND METHODS}

The current study is a retrospective descriptive study of 243 cases of exclusive endoscopic surgery of cholesteatoma disease, performed by the same surgeon in a span of 8 years in a medical college. The aim of the study was to define the exclusive endoscopic cholesteatoma surgery. The classification and grading of cholesteatoma was done as per Daniele Marchioni and Livio Presutti and the staging system of Telmesani et al modified by Daniele Marchioni and Livio Presutti. The cases comprised of cholesteatoma disease confined to attic, middle ear and mastoid. Cases were operated exclusively with Endoscopy.

\section{RESULTS}

All cases were operated exclusively with endoscopic trans-canal approach only in 191 cases and with extension by endoscopic endaural technique in 52 cases. All were done under local anaesthesia with sedation. Age group of cases was from 8-65 years (median age was 20 years). There were 182 males and 61 females. Follow up of cases were done from 12 months to 7 and half years. There were no cases of recurrence. Cavity problems were minimal.

\section{CONCLUSION}

Endoscope can be used as a stand-alone means of cholesteatoma surgery with improved results.

\section{KEY WORDS}

Cholesteatoma Surgery, Endoscopic, Exclusive.

HOW TO CITE THIS ARTICLE: Potsangbam DS. Exclusive endoscopic cholesteatoma surgery. J. Evolution Med. Dent. Sci. 2019;8(03):163-169, DOI: 10.14260/jemds/2019/36

\section{BACKGROUND}

Microscope had been the mainstay of cholesteatoma surgery since the middle of the twentieth century. Since the early part of the nineties endoscopic surgery for middle ear and attic cholesteatoma had been started by few surgeons with good results. In spite of great resistance from the microscopic surgeons, the use of endoscope has been accepted by many as an adjunct to microscopic surgery for cholesteatoma at the present state. Cholesteatoma is a disease originating in the attic and the posterior quadrant of the pars tensa tympanic membrane. The advancement in equipment and techniques of diagnosis of ear diseases has allowed early diagnosis of the cholesteatoma disease in the last few decades. Thus, the incidence of complications arising out of cholesteatoma diseases is rapidly decreasing. The early cholesteatoma diseases are best treated by starting the tacking of the disease from the area of origin.

'Financial or Other Competing Interest': None.

Submission 30-10-2018, Peer Review 07-01-2019,

Acceptance 14-01-2019, Published 21-01-2019.

Corresponding Author:

Dhakeswar Singh Potsangbam,

Singjamei Chingamakha, Heirangoithong Bazar,

Imphal-795001, Manipur, India.

E-mail: potsangbamdhakeswarsingh@gmail.com dhake7@yahoo.com

DOI: $10.14260 /$ jemds $/ 2019 / 36$

\section{(c) $(1) \ominus$}

This helps in reducing post-operative complications of large mastoidectomy cavities with consequent problems like frequent infections, inability to enter water sports, swimming and diving. Microscopic inside out mastoidectomy starting from atticotomy is an improvement in microscopic cholesteatoma surgery. But the advantages of endoscope are increased visualization of corners, mobility of the endoscope tip in the operating field and $360^{\circ}$ visualization of the operative field. This study has been done to observe the endoscopic surgery in treatment of cholesteatoma in avoiding complications and exposure of large and extensive cholesteatoma using only endoscopes.

\section{MATERIALS AND METHODS}

The study was Retrospective descriptive study of endoscopic cholesteatoma surgeries done in 243 ears in a duration of eight years from 2009 to 2017. The following are the criteria of case selection-

\section{Staging of Cholesteatoma}

Our study used staging of the attic cholesteatoma as per Daniele Marchioni and Livio Presutti.[1]

\section{Inclusion Criteria}

The sites of cholesteatoma involving all of the given below: Site: (a) Lateral attic (with anterior epitympanum) and (b) Medial attic. - Subsites: (a) Mesotympanum, 
Protympanum, (c) Hypotympanum, (d) Retrotympanum, (e) Antrum and (f) Mastoid. - I Extensiono C1: cholesteatoma with limited attic extension, - C1a: cholesteatoma involving only the lateral attic, - C1b: cholesteatoma involving also the medial attic. $\bigcirc \mathrm{C} 2$ : cholesteatoma with extension in one or more subsites, -C2a: posterior extension to the antrum and mastoid, - C2b: inferior extension to the mesotympanic, protympanic and hypotympanic regions- C2c: both posterior and inferior extension. $\mathrm{O}$ C3: cholesteatoma involving the retrotympanic space (Sinus tympani/subtympanic sinus; subpyramidal space) and/or with facial nerve involvement. For Mesotympanic and Acquired Cholesteatoma, the cases were selected from the staging system of Telmesani et al modified by Daniele Marchioni and Livio Presutti as given below-

- $\mathrm{T}=$ Tympanic cavity (Mesotympanic spaces), $0 \mathrm{~T} 1=$ mesotympanum involvement without hidden recess involvement (Hypotympanum, retrotympanum, protympanum), $\circ \mathrm{T} 2$ =mesotympanic cholesteatoma with one hidden recess involvement (Hypotympanum, retrotympanum, protympanum) and $\circ \mathrm{T} 3=2$ or more hidden recess involvements

- $\quad \mathrm{A}=$ Attic: $\circ \mathrm{A} 0=$ no attic involvement, $\circ \mathrm{A} 1=$ lateral attic involvement, $\circ \mathrm{A} 2=$ medial attic involvement and $\circ \mathrm{A} 3=$ entire attic involvement
- $\mathrm{M}=$ Mastoid: $\circ \mathrm{M} 0=$ no mastoid involvement, $\circ \mathrm{M} 1=$ antrum cholesteatoma, $\circ \mathrm{M} 2=$ cholesteatoma extending beyond the antrum and $\circ \mathrm{M} 3=$ cholesteatoma affects the whole mastoid cavity.

\section{Exclusion Criteria}

Cases involving the petrous apex, inner ear and intracranial complications are excluded from the study. Cases allergic to lignocaine, suffering from hyperglycaemia, hypertension, pathological problems of kidney, liver and heart; suffering from hepatitis B and C, HIV infection etc. are also excluded from the study. This was Retrospective descriptive study of exclusive endoscopic cholesteatoma removal in 8 years duration from 2009 to 2017.

\section{Principle of Endoscopic Cholesteatoma Surgery}

For proper surgery of the middle ear cholesteatoma, the classification of the compartments of the middle ear is done as-

1. Epitympanum- a. Anterior, b. Posterior, c. Prussak's Space.

2. Mesotympanum.

3. Protympanum.

4. Retrotympanum.

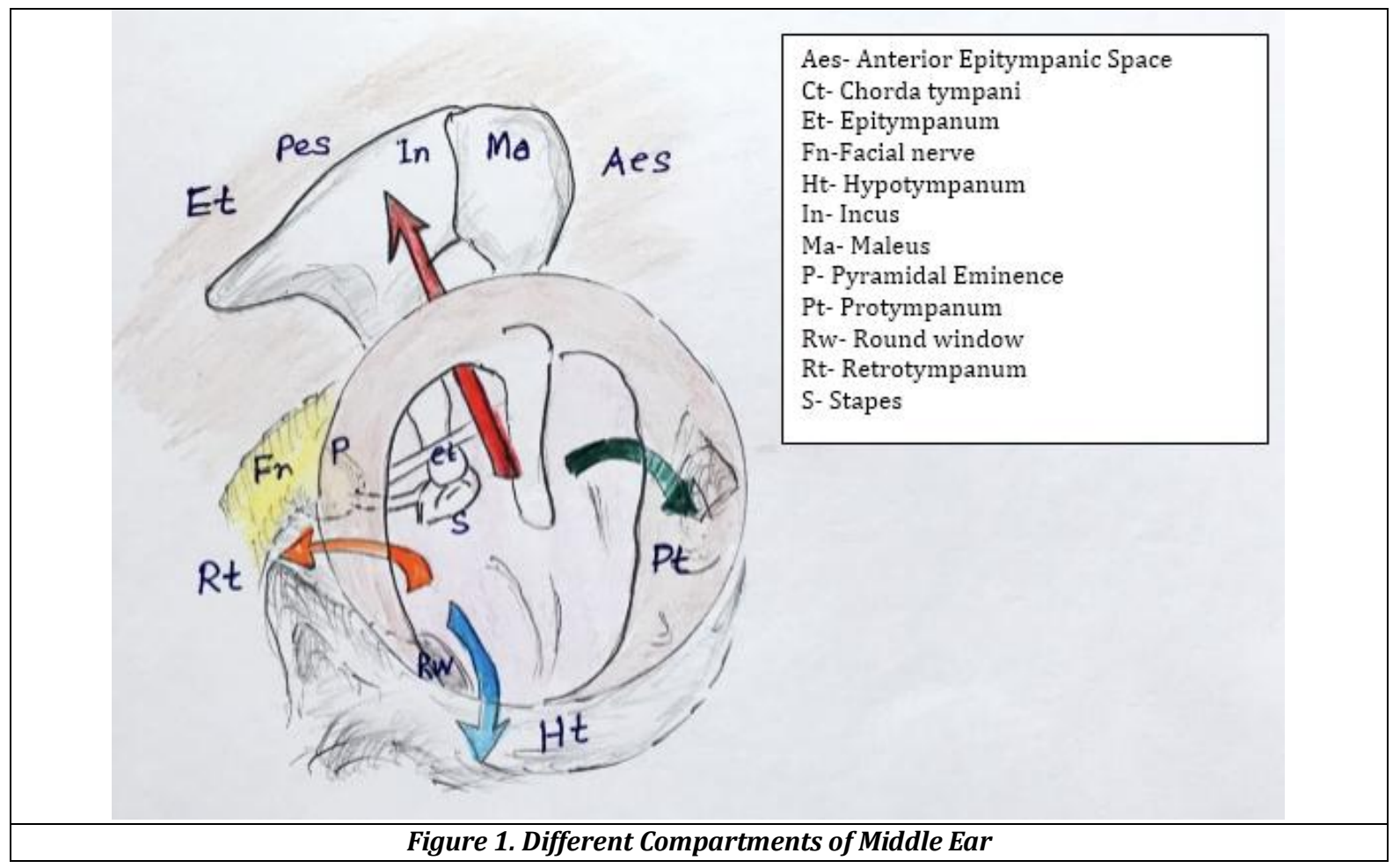

Ventilation of Various Compartments of the Middle Ear Cleft Are Affected in This Manner:

1. Epitympanum-

a. Anterior compartment from isthmus or through Tensor Tympani Fold if incomplete,

b. Posterior compartment from Isthmus,

c. Prussak's Space from Eustachian tube (ET) lateral to posterior malleolar ligament.

2. Mesotympanum from ET

3. Protympanum from ET

4. Retrotympanum from ET.

The failure of ventilation of the various compartments is the cause of retraction pocket formation and subsequent development of cholesteatoma. Therefore, it is imperative to look for adequacy of ventilation pathways at the end of cholesteatoma surgery of middle ear and attic. 


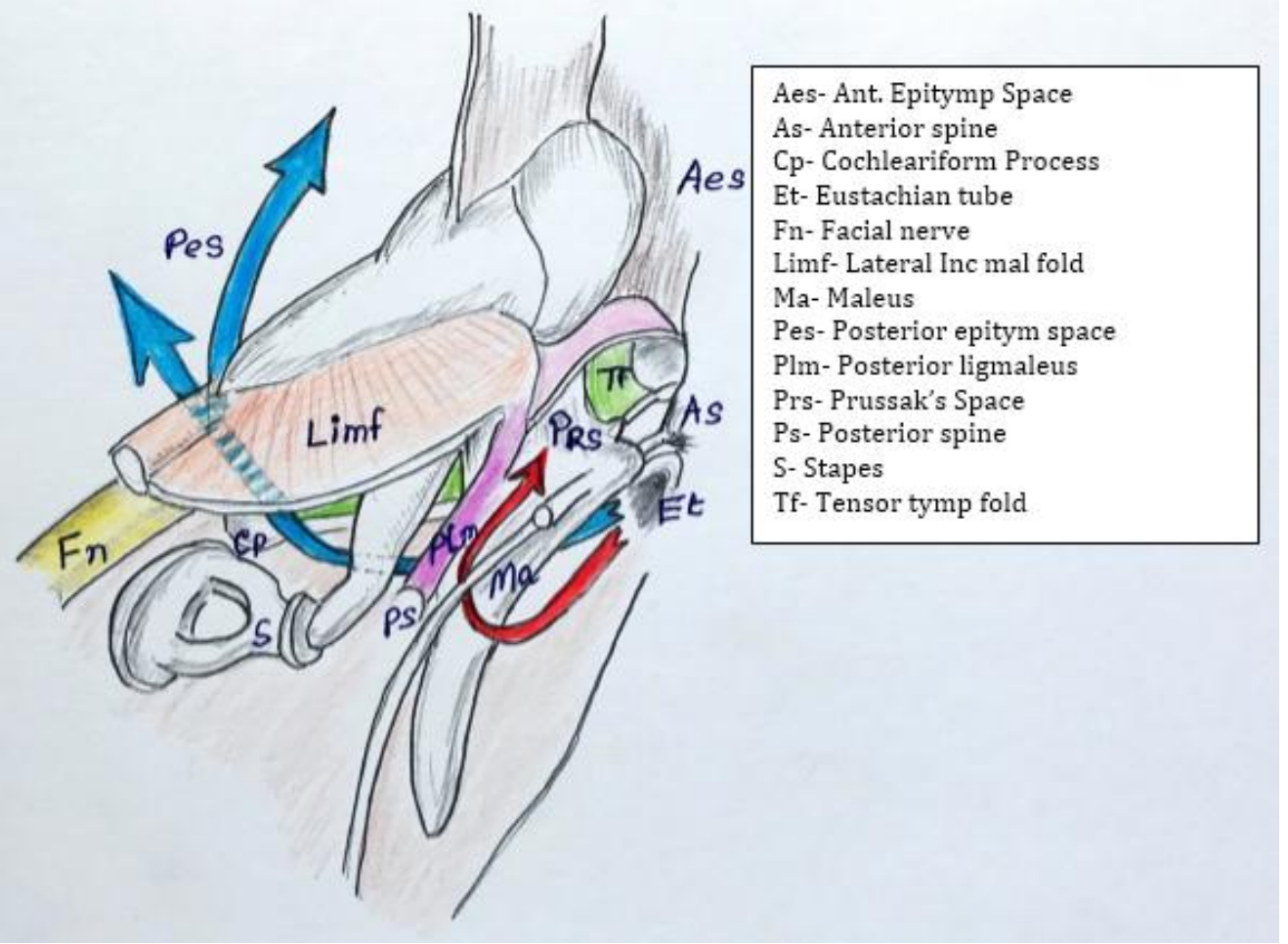

Figure 2. Ventilation Pathways in Middle Ear Cavity

The Principles of Cholesteatoma Surgery Are, To Aim For:

1. Eradication of cholesteatoma

2. Adequacy of ventilation pathways of various middle ear, attic and mastoid compartments

3. Reconstruction of hearing mechanism

4. Avoiding cavity problems.

Under endoscopic vision, structures of the middle ear became clear and exposure became easy for difficult areas: (1). Sinus Tympani: variation of shape and depth: types A, B and C; (2). Variations in structures of (a). Ponticulus, (b). Subiculum, (c). Finiculus, (d). Pyramidal eminence, (e). Subpyramidal space, (f). Sinus Subtympanicus, (g). Supratubal Recess.

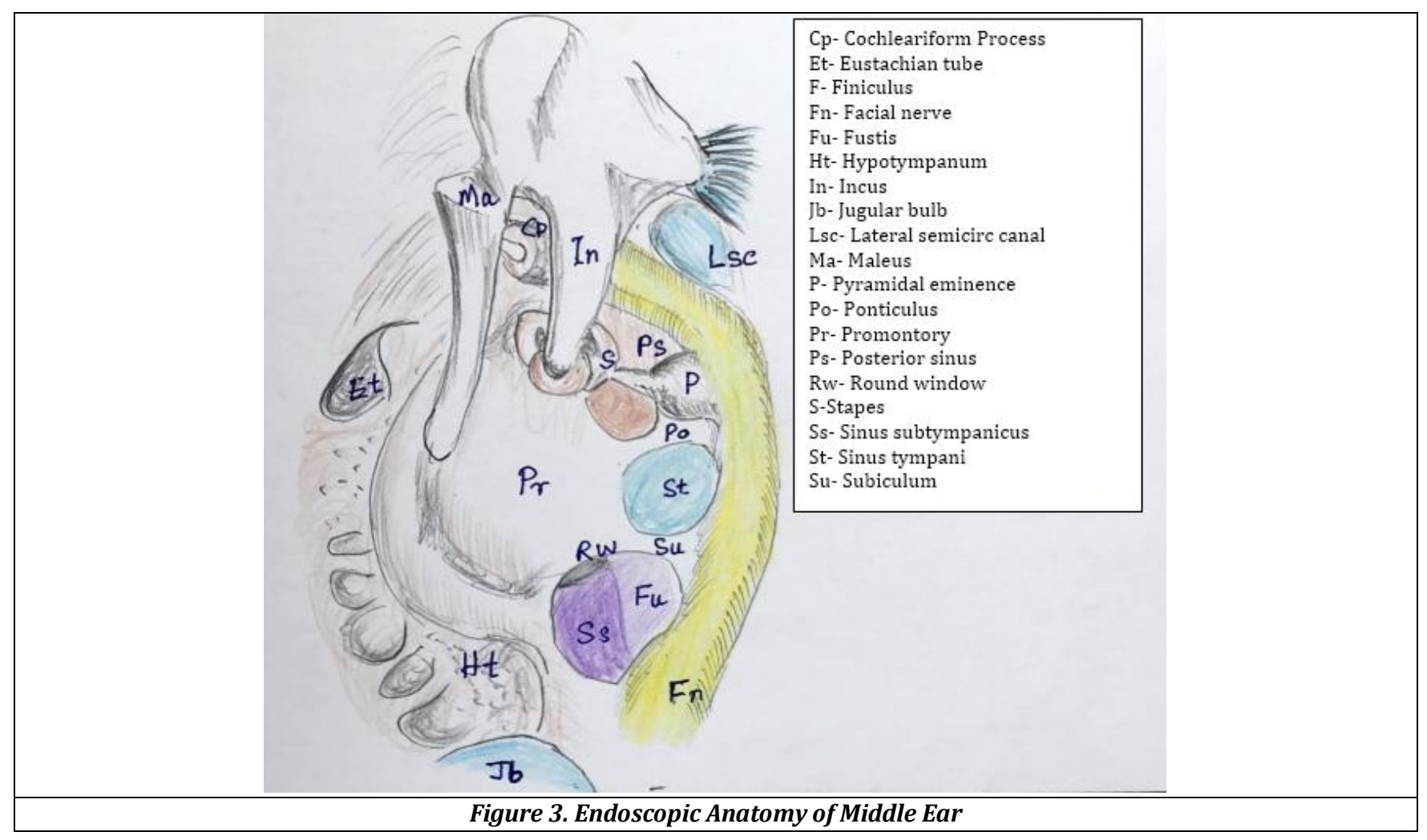




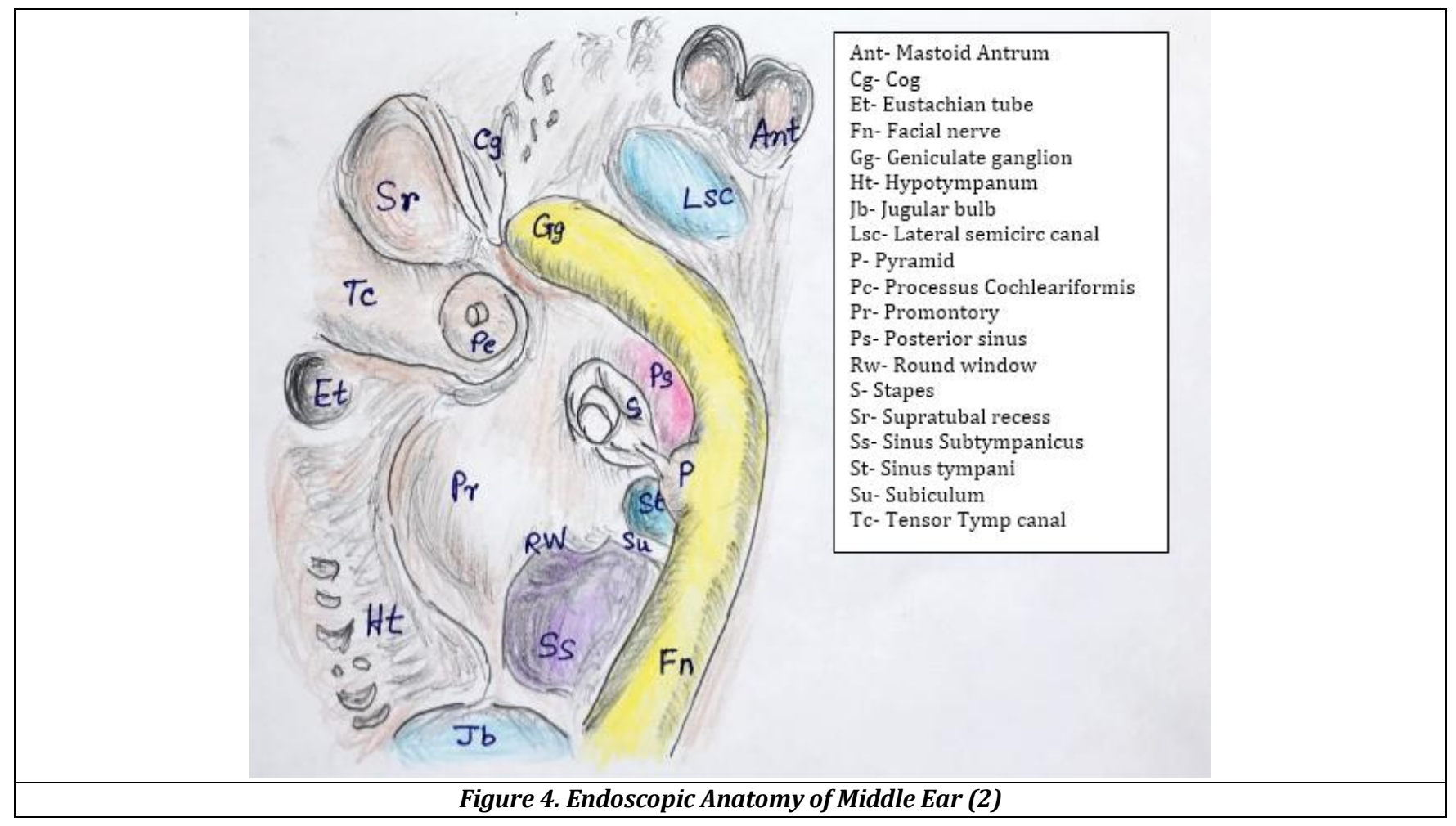

Special endoscopic ear surgery instruments and specially made curved instruments with suction attachments and angled drill handpiece with self-irrigation (by Smith \& Nephew co.(R)) are useful for ease of exposure and dissection. $3 \mathrm{~mm} 11-15 \mathrm{~cm} 0^{0}, 30^{\circ}$, $45^{0}$ endoscopes are especially useful for the negotiation in the isthmus, sinus tympani, subpyramidal space, sinus subtympanicus, mastoid tip, retrofacial cells etc.

\section{Operation Procedure}

All surgeries were done in local anaesthesia. Premedication was given with injection ondansetron (Adults: 4-8 mg. and children: 4 mg. slow intravenous), promethazine (Adults: $25 \mathrm{mg}$ and children $6.25-12.5 \mathrm{mg}$. slow intravenous), glycopyrrolate (4 mcgm/Kg slow intravenous) and tramadol (Adults: 50-100 mg and children: 25-50 mg intramuscular) about 30-60 minutes before surgery. Local anaesthesia was given in the form of $2 \%$ lignocaine with adrenaline $(1: 30,000)$ for local infiltration and $4 \%$ lignocaine with adrenaline $(1: 10,000)$ for surface anaesthesia and blood haemostasis.

After the patient was kept in the supine position with a soft pillow under the head, the face was turned away from the surgeon. After proper antiseptic dressing, a plastic adhesive draping with a hole for the pinna was used to cover the operating area along with large cotton cut-out sheets covering the remaining part of the whole body. Under endoscopic guidance $0.4 \mathrm{ml}$ of $2 \%$ lignocaine adrenaline infiltration was done at 12, 3, 6 and 9 0'clock positions in the osteo-cartilaginous junction of the external canal. Further infiltrations were given in the incisura terminalis, around upper end of pinna and all around the mastoid along post-auricular sulcus about $0.5 \mathrm{ml}$ for every $1 \mathrm{~cm}$ distance.

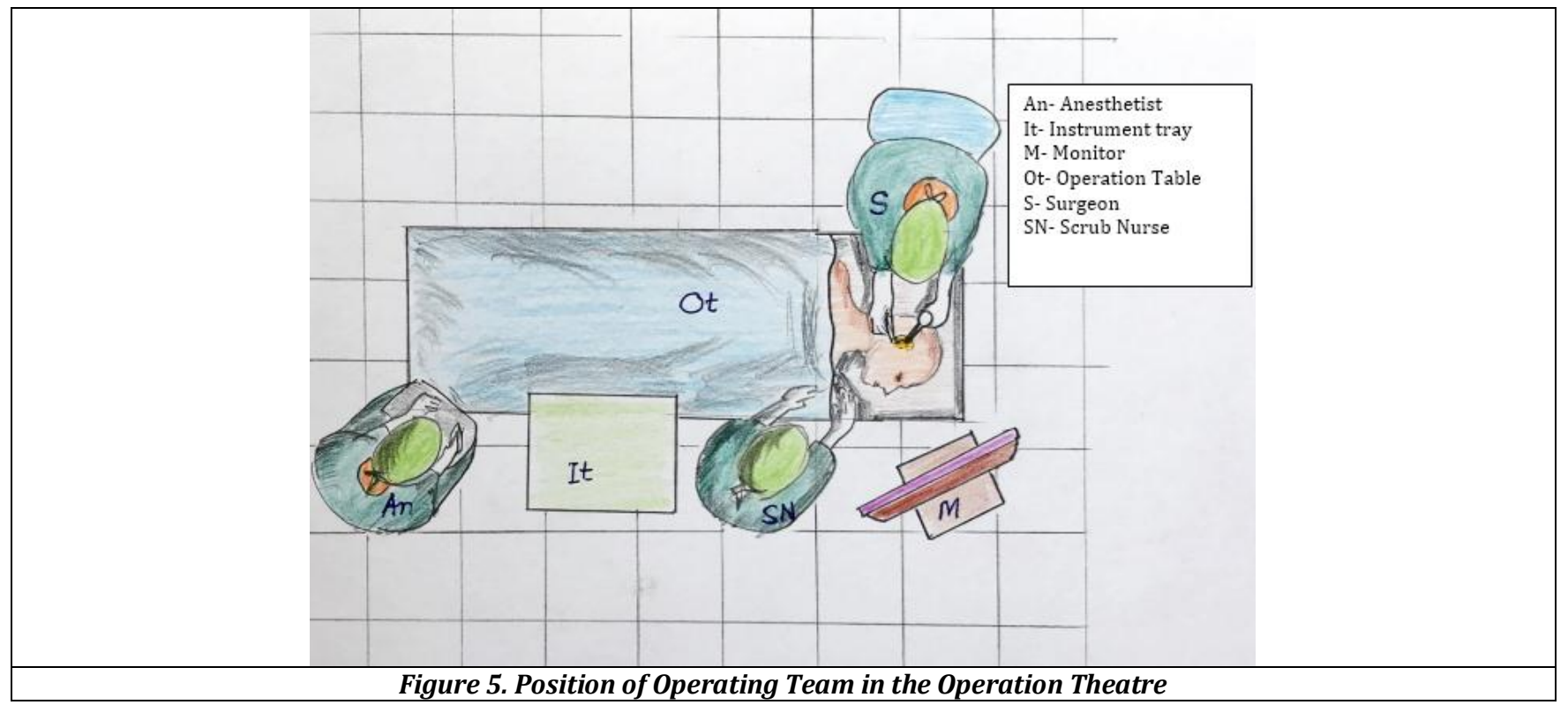


Usual incision was from 7 to 3 O'clock position clockwise on the right ear and 4 to 9 O'clock position anticlockwise on the left ear at the osteo-cartilaginous junction or hairline (About 1.5 to $2 \mathrm{~cm}$ lateral to annulus) of the external canal. The incision was deepened to the bone and elevated medially and inferiorly up to the fibrous annulus of the tympanic membrane and the tympanic membrane was reflected inferiorly up to the umbo. This exposes the attic, protympanum, retrotympanum and some part of mesotympanum revealing the ossicular chain. Retraction pockets and C1a cholesteatoma were easily removed here. This exposure were also enough for C1a (Lateral epitympanum and Prussak's space lesions), C2b (Mesotympanum, Protympanum, sinus tympani and Hypotympanum cholesteatomas), C2c (Posterior and inferior extensions) lesions and C3 cholesteatoma involving retrotympanic space (Sinus tympani/subtympanic sinus; subpyramidal space) and or with facial nerve involvement.

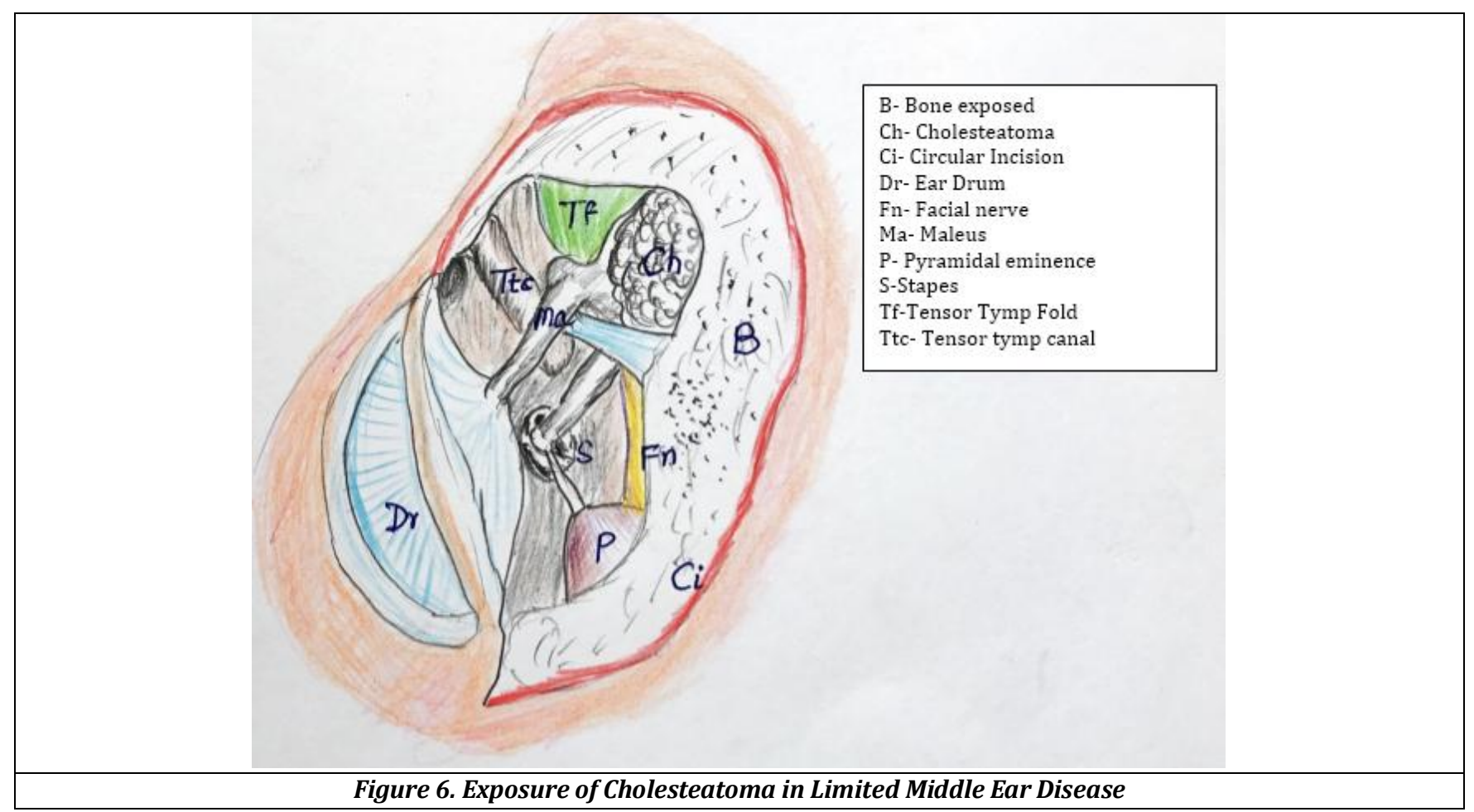

Removal of head of Malleus and body of Incus or Incus completely with dislocation of Incudo-stapedial joint and removal of scutum was done for $\mathrm{C} 1 \mathrm{~b}$ cholesteatoma (medial attic).

A radial incision starting at 10 'clock on right ear and 11 0'clock on left ear drawn laterally towards incisura terminalis and soft tissues retracted after adequate mastoid bone exposure: Endaural extension was used for C2a (Posterior extension to the antrum and mastoid) lesions. But if the mastoid is sclerotic, this endaural exposure was not needed.

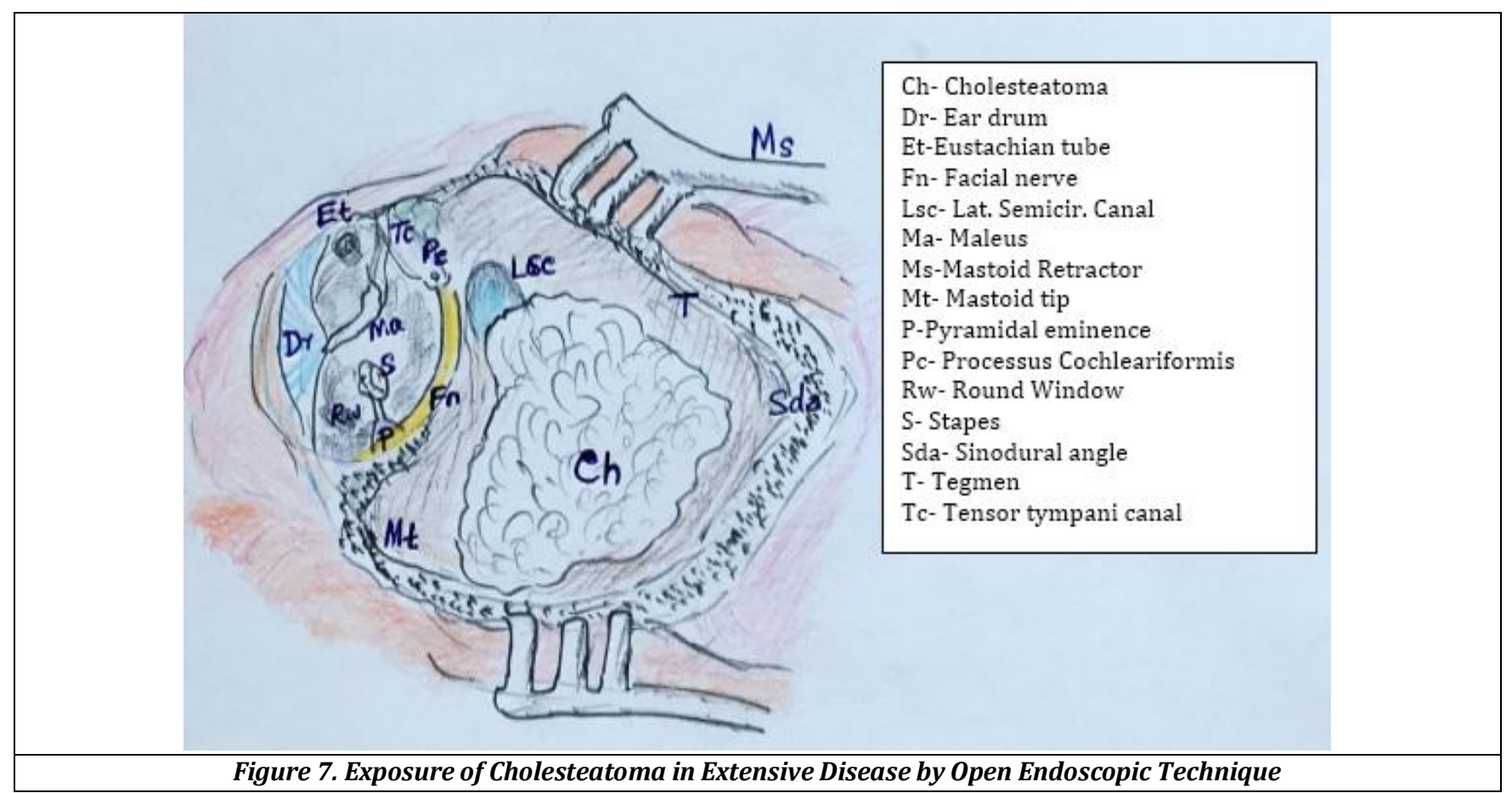


A set of variable sized sturdy and sharp bone curettes of little curvature in the end was effectively employed to expose small antrum, aditus and attic. Only in very pneumatised mastoid with wide extension up to the mastoid tip, extension of incision by endaural approach and drilling under endoscopy was needed. Dry drilling was enough to expose the whole of extensive mastoid.

\section{Statistical Analysis}

Collected data was entered into MS-Excel and data cleansing was performed. Data was then transferred into IBM SPSS ver22.0 software and analysed. Descriptive statistics like Mean, Median, Standard deviation and percentage were used. Analytical Statistics like Chi square by using Yates' correction formula and ANOVA F-test was applied. P-value of $<0.05$ was taken as statistically significant.

\section{RESULTS}

This was Retrospective descriptive study of exclusive endoscopic cholesteatoma removal, all done by the author in JNIMS, Imphal in 8 years duration from 2009 to 2017 in 243 ears. Attic cholesteatoma cases encountered were from stages C1a to C3 only. Cases of involvement of labyrinth, petrous temporal bone and intracranial compartments were not encountered. Cases were operated exclusively with Endoscopic Trans-canal only in $78.6 \% \%$ (191) cases and with Extension by endaural inside-out technique in $21.4 \%$ (52) cases. All were done under local anaesthesia with sedation. Age group of cases were from 8-65 years (median age was 30 years). There were $74.9 \%$ (182) males and $25.1 \%$ (61) females. All cases under 20 years 41.6\% (101 cases) were operated in two stages at six months interval. Age and sex distribution were significant at the $5 \%$ C.I. Table 2 shows the distribution of cases were $9.9 \%$ (24 cases) of C1a, 20.2\% (49 cases) of C1b, $60 \%$ (146) of C2a, 7\% (17 cases) of C2b, 1.6\% (4 cases) of C2c and 1.2\% (3 cases) of C3: 3. -value of $<0.05$ was taken as statistically significant.

\begin{tabular}{|c|c|c|c|}
\hline \multirow{2}{*}{ Age-wise } & \multicolumn{2}{|c|}{ Sex } & \multirow{2}{*}{ Total } \\
\cline { 2 - 3 } & Male (\%) & Female (\%) & \\
\hline$<20$ & $79(78.2)$ & $22(21.8)$ & 101 \\
\hline $20-40$ & $44(63.8))$ & $25(36.2)$ & 69 \\
\hline $40-60$ & $44(75.9)$ & $14(24.1)$ & 58 \\
\hline$\geq 60$ & $15(100)$ & $0(0.0)$ & 15 \\
\hline Total & $\mathbf{1 8 2}(\mathbf{7 4 . 9 )}$ & $\mathbf{6 1}(25.1)$ & $\mathbf{2 4 3}$ \\
\hline \multicolumn{3}{|c|}{ Table 1. Age and Sex Distribution } \\
\hline \multicolumn{3}{|c|}{$\chi^{2}=10.194$ with 3d.f; P-Value $=0.017<0.05$} \\
\hline
\end{tabular}

\begin{tabular}{|c|c|c|}
\hline Stage of Cholesteatoma & No. of Cases & Percentage \\
\hline C1a & 24 & $09.9 \%$ \\
\hline C1b & 49 & $20.2 \%$ \\
\hline $\mathrm{C} 2 \mathrm{a}$ & 146 & $60.1 \%$ \\
\hline $\mathrm{C} 2 \mathrm{~b}$ & 17 & $07.0 \%$ \\
\hline $\mathrm{C} 2 \mathrm{c}$ & 4 & $01.6 \%$ \\
\hline $\mathrm{C} 3$ & 3 & $01.2 \%$ \\
\hline Total & 243 & 100 \\
\hline
\end{tabular}

\begin{tabular}{|c|c|c|c|c|c|c|}
\hline 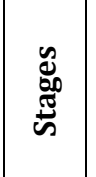 & 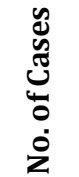 & 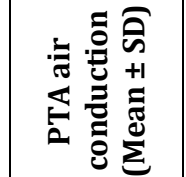 & $\Xi$ & $\sum^{\frac{x}{\pi}}$ & $\frac{\mathscr{0}}{\frac{0}{\sigma}}$ & $\begin{array}{l}\stackrel{0}{\Xi} \\
\stackrel{\pi}{2} \\
\stackrel{1}{2}\end{array}$ \\
\hline C1a & 24 & $25.27 \pm 5.76$ & 15.0 & 36.6 & \multirow{6}{*}{48.840} & \multirow{6}{*}{0.000} \\
\hline $\mathrm{C} 1 \mathrm{~b}$ & 49 & $43.42 \pm 5.18$ & 23.3 & 50.0 & & \\
\hline $\mathrm{C} 2 \mathrm{a}$ & 146 & $50.48 \pm 8.37$ & 25.0 & 90.0 & & \\
\hline $\mathrm{C} 2 \mathrm{~b}$ & 17 & $47.54 \pm 7.29$ & 40.0 & 65.0 & & \\
\hline $\mathrm{C} 2 \mathrm{c}$ & 4 & \begin{tabular}{|c|}
$64.57 \pm$ \\
20.69 \\
\end{tabular} & 40.0 & 90.0 & & \\
\hline C3 & 3 & $\begin{array}{c}52.21 \pm \\
10.57\end{array}$ & 40.0 & 58.0 & & \\
\hline Total & 243 & $\begin{array}{c}46.61 \pm \\
11.05\end{array}$ & 15 & 90 & & \\
\hline
\end{tabular}

Table 3 shows that mean PTA air conduction in the C1a stage was $25.27 \pm 5.76$ while the mean PTA air condition in the $\mathrm{C} 2 \mathrm{C}$ stages was $64.57 \pm 20.69$. PTA air conduction in the different stages was significant. Table 4 also shows that mean PTA bone condition in the C1a stage was $25.27 \pm 5.76$ while the mean PTA air condition in the $\mathrm{C} 2 \mathrm{C}$ stages was $11.17 \pm$ 8.48. PTA bone conduction in the different stages was significant.

\begin{tabular}{|c|c|c|c|c|c|c|}
\hline 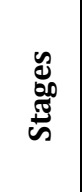 & 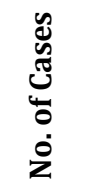 & 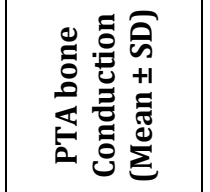 & $\Sigma$ & 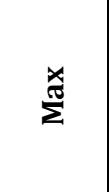 & 芳 & 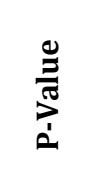 \\
\hline $\mathrm{C} 1 \mathrm{a}$ & 24 & $6.87 \pm 3.85$ & 1.66 & 13.33 & \multirow{6}{*}{7.38} & \multirow{6}{*}{0.000} \\
\hline C1b & 49 & $6.29 \pm 3.47$ & 1.66 & 15.0 & & \\
\hline $\mathrm{C} 2 \mathrm{a}$ & 146 & $11.17 \pm 8.48$ & 1.66 & 50.0 & & \\
\hline $\mathrm{C} 2 \mathrm{~b}$ & 17 & $9.40 \pm 7.04$ & 1.66 & 28.33 & & \\
\hline $\mathrm{C} 2 \mathrm{c}$ & 4 & $25.63 \pm 21.46$ & 3.33 & 50.0 & & \\
\hline C3 & 3 & $7.22 \pm 4.81$ & 1.66 & 10.0 & & \\
\hline Total & 243 & $9.83 \pm 8.05$ & 1.66 & 50 & & \\
\hline
\end{tabular}

\begin{tabular}{|c|c|c|}
\hline Ossicular Configuration & No. of Cases & Percentages \\
\hline HMBI- & 11 & $4.5 \%$ \\
\hline I- & 1 & $0.4 \%$ \\
\hline LI- & 1 & $0.4 \%$ \\
\hline $\mathrm{M}+\mathrm{I}+\mathrm{S}$ & 27 & $11.1 \%$ \\
\hline $\mathrm{M}+\mathrm{S}$ & 11 & $4.5 \%$ \\
\hline $\mathrm{M}+\mathrm{SF}$ & 2 & $0.8 \%$ \\
\hline $\mathrm{PM}+\mathrm{S}$ & 2 & $0.8 \%$ \\
\hline $\mathrm{S}$ & 129 & $53.1 \%$ \\
\hline SF & 59 & $24.3 \%$ \\
\hline Total & 243 & 100 \\
\hline \multicolumn{3}{|c|}{$\begin{array}{c}\text { Table 5. Distribution of Ossicular Configuration in Various } \\
\text { Stages of Cholesteatoma }\end{array}$} \\
\hline
\end{tabular}

Legend for ossicular configuration designated in the table 5 can be expanded as: HMBI- = Absent head of the malleus and body of incus by erosion. I- = Incus absent. LI- = Lenticular process of incus absent. $\mathrm{M}+\mathrm{I}+\mathrm{S}=$ Malleus, incus and stapes all intact. $\mathrm{M}+\mathrm{S}=$ Only Malleus and stapes present. $\mathrm{M}+\mathrm{SF}=$ Malleus and stapes footplate present, but, stapes superstructure eroded. $\mathrm{PM}+\mathrm{S}=$ Partial malleus and whole 
stapes present. $\mathrm{S}=$ Only whole of stapes present. SF = Only stapes footplate present.

Complications most prevalent were pain around the ear complained by some patients. Next in incidence were cavity problems of discharge and debris collection needing cleaning minimum once in 6 months in about 12 cases. Reason of most cases with complication occurring in early part of the study may be due to learning curve or leaving of mucosa or bony overhang. Most got cured in later minor revision surgeries. Temporary facial nerve weaknesses seen in 3 cases, fully recovered later. In later cases, employment of soft canal wall reconstruction by tragal or conchal cartilage and obliteration of the large mastoid cavities by temporalis muscle, cartilage or bone lead to reduction of cavity problems. The follow up duration ranged from 12 months to 7 years and 9 months. There was no recurrence of the cholesteatoma during the whole duration of follow up.

\section{DISCUSSION}

Traditional cholesteatoma surgery employed microscopic surgery till the late 1990's when endoscope came into the picture. Canal wall up (CWU) and canal wall down (CWD) surgeries were usually employed to achieve cholesteatoma eradication. Endoscopy has been accepted as an adjunct to cholesteatoma surgery. Visualization of entire middle ear space was difficult under microscopy and field of vision was limited by the narrowest segment. Hidden areas like sinus tympani, facial recess, anterior epitympanum, attic, hypotympanum and protympanum was the common areas of leaving residual cholesteatoma. Employment of endoscope had improved the field of vision by giving a panoramic view, passing through the narrowest segments and showing the hidden areas.[2] Employment of endoscope as an adjunct to cholesteatoma surgery had reduced the incidences of residual cholesteatoma in CWU surgery (Up to 47\%) and CWD (Above $10 \%)$ to less than $6 \%,[3,4,5,6,7]$ The occurrence of residual cholesteatoma were due to insufficient primary resection because of (1) very thin epidermal matrix or middle ear inflammation and (2) limited exposure of hidden areas, limited by the narrowest segment in surgery under microscope. This had prompted combined approach tympanoplasty through mastoid and posterior tympanotomy. Persistence of physio-pathologic phenomena that determined cholesteatoma development should be avoided to avoid recurrence of the disease by avoiding tympanic membrane retractions.[1] Ventilation of different compartments of the middle ear cleft and adequate reconstruction of scutum should be achieved at the end of cholesteatoma surgery. Exclusive endoscopic cholesteatoma surgeries have not been practised unless in limited attic and middle ear cholesteatomas.[8,9,10] In our study, trans canal curetting of bone was employed in small mastoid antrum with effective exposure and drilling of bone after endaural extension in some cases with very pneumatised mastoids. In this study series, it was possible to eradicate all cases of cholesteatomas presented to the surgeon in a span of eight years, by pure endoscopic approach without any need for microscope usage. Longest follow up time was 8 years and shortest was 12 months. There were no cases of recurrence of cholesteatoma.
Our study was aimed at establishing the point that only endoscope can effectively treat cholesteatoma disease of the ears. The routine examination of the ear by endoscopy has increased chances of early diagnosis and treatment leading to avoidance of very complicated and advanced spread of the disease in the petrous apex and labyrinth. In our study, we didn't come across this advanced spread of the disease, and, this may be the reason why we could employ endoscopic approach effectively.

\section{CONCLUSION}

Routine examination of the ear by endoscopy has enabled early diagnosis of cholesteatoma disease of the ear. Excellent visualization of the hidden areas of the middle ear has greatly removed recurrence of cholesteatoma from the middle ear cavity. Transcanal endoscopic approach reduces the size of post-operative open cavity of mastoid leading to avoidance of cavity problems. Soft tissue reconstruction after mastoidectomy could be done endoscopically and reduced cavity problems. Endaural extension of the incision allowed endoscopic surgery to reach the far corners of a well pneumatised mastoid and thus cholesteatoma surgery can be performed exclusively with endoscopy alone.

\section{REFERENCES}

[1] Presutti L, Marchioni D. Endoscopic ear surgery principles, indications and techniques. Georg Thieme Verlag 2015, (ISBN 9783131630414).

[2] Presutti L, Gioacchini FM, Alicandri-Ciufelli M, et al. Results of endoscopic middle ear surgery for cholesteatoma treatment: a systematic review. Acta Otorhinolaryngol Ital 2014;34(3):153-7.

[3] Yung MM. The use of rigid endoscopes in cholesteatoma surgery. J Laryngol Otol 1994;108(4):307-9.

[4] Thomassin JM, Korchia D, Doris JM. Endoscopic-guided otosurgery in the prevention of residual cholesteatoma. Laryngoscope 1993;103(8):939-43.

[5] Badr-el-Dine M. Value of ear endoscopy in cholesteatoma surgery. Otology \& Neurotology 2002;23(5):631-5.

[6] Sajjadi H. Endoscopic middle ear and mastoid surgery for cholesteatoma. Iranian Journal of Otorhinolaryngology 2013;25(71):63-70.

[7] Aoki K. Advantages of endoscopically assisted surgery for attic cholesteatoma. Diagnostic and Therapeutic Endoscopy 2001;7(3-4):99-107.

[8] Kanzara T, Virk JS, Chawda S, et al. Wholly endoscopic permeatal removal of a petrous apex cholesteatoma. Case Reports in Otolaryngology 2014;(2014):184230. http//dx.doi.org/10.1155/2014/184230.

[9] Tarabichi M. Endoscopic transcanal middle ear surgery. Indian Journal of Otolaryngology Head and Neck Surgery 2010;62(1):6-24.

[10] Tarabichi M, Nogueira JF, Marchioni D, et al. Transcanal endoscopic management of cholesteatoma. Otolaryngology Clinics North America 2013;46(2):107-30. 